\title{
Zniekształcenia modulacyjne filtrów cyfrowych - modeli linii długiej
}

Streszczenie. W artykule na operatorowym równaniu różniczkowym jednorodnej linii długiej dokonano przekształcenia digitalizującego otrzymując filtr cyfrowy - model linii. Filtry cyfrowe modelu nie sa filtrami typu wymiernego. Sa to mianowicie filtry pierwiastkowe $i$ wykładniczo-pierwiastkowe. Artykuł idzie jednak dalej i zajmuje się problemem zniekształcenia filtrów - modeli linii długiej - zachodzącego w procesie modulacji sygnałów nośnych.

Abstract. In the article differential operator equation of the homogenous transmission line has been digitally converted to give digital filter transmission line model. These models aren't rational type of filters, in fact they are root and exponential-root filters. This article goes further and deals with the problem of filter's distortion - transmission line models - which takes place during the modulation of carrier signals. (Modulation distortion of digital filters - transmission line models)

Słowa kluczowe: linia długa, operatory rzędu ułamkowego, filtry funkcyjne, modulacja

Keywords: transmission line, fractional order operators, function filters, modulation

\section{Wprowadzenie - filtry funkcyjne - pojęcia podstawowe}

Cyfrowy filtr przyczynowy $A$, utożsamiany $z$ rzeczywisto-liczbowym ciągiem $\left\{A_{n}\right\}_{n=0}^{\infty}$ albo z funkcją:

$$
A(z)=\sum_{n=0}^{\infty} A_{n} z^{n}, z \in \mathbf{C},
$$

działa na sygnał $x$ utożsamiany $z$ ciągiem $\left\{x_{n}\right\}_{n=-\infty}^{\infty}$ według prawa splotowego:

$$
(A x)_{n}=\sum_{m=0}^{\infty} A_{m} x_{n-m} .
$$

Jeżeli $f(z)$ jest funkcją zmiennej zespolonej, to przyczynowy filtr $f(A)$ nazywany filtrem funkcyjnym utożsamiany będzie z ciągiem [5]:

$$
\left\{(f(A))_{n}\right\}_{n=0}^{\infty}
$$

takim, że:

$$
(f(A))(z)=f(A(z))=\sum_{n=0}^{\infty}(f(A))_{n} z^{n},
$$

oraz:

$$
(f(A))_{n}=\left.\frac{1}{n !} \frac{d^{n} f(A(z))}{d z^{n}}\right|_{z=0} .
$$

Filtr funkcyjny działa na sygnał $X$ również według prawa splotowego:

$$
(f(A) x)_{n}=\sum_{m=0}^{\infty}(f(A))_{m} x_{n-m} .
$$

Ze wzorów (4) i (1) wynika też wyrażenie na warunek początkowy ciągu wagowego (3) filtru funkcyjnego:

$$
(f(A))_{0}=f\left(A_{0}\right)
$$

Formuła (5) w zastosowaniu do wyznaczania współczynników wagowych filtrów funkcyjnych nie jest wygodna. Ma ona zastosowanie tylko do stosunkowo prostych filtrów jakimi są na przykład filtry różniczkujące rzędu $-1 \leq p \leq 1$, tj. $(a-z)^{p}$. Wówczas zastosowanie formuły (5) daje użyteczny wynik [2][3]:

$$
\left((a-z)^{p}\right)_{n}=a^{p} a^{-n} \prod_{m=1}^{n} \frac{m-1-p}{m} .
$$

Filtr taki nazywa się też całko-pochodnym filtrem rzędu $p$ z zero-biegunem $a$.

Dla filtrów funkcyjnych bardziej złożonych lepsze rezultaty daje formuła uwikłana [5]:

$$
(f(A))_{n}=\sum_{m=1}^{n} \frac{m}{n} A_{m}\left(\frac{d f}{d A}\right)_{n-m},
$$

która dla pewnych funkcji $f(A)$ może przejść w formułę rekurencyjną. Przykładowo ma to miejsce dla funkcji wykładniczej $e^{A}$, która jest idempotentem względem operacji różniczkowania:

$$
\left(e^{A}\right)_{n}=\sum_{m=1}^{n} \frac{m}{n} A_{m}\left(e^{A}\right)_{n-m} .
$$

Warunek początkowy dla ciągu $\left\{e^{A}\right\}_{n}$ otrzymuje się ze wzoru (7):

$$
\left(e^{A}\right)_{0}=e^{A_{0}}
$$

Wskaźniki $n: n=1,2,3, \ldots$.

\section{Model cyfrowy linii długiej}

Równania różniczkowe o pochodnych cząstkowych linii długiej mają postać: 


$$
\begin{gathered}
\frac{\partial u}{\partial \dot{x}}=R i+L \frac{\partial i}{\partial t} \\
\frac{\partial i}{\partial \dot{x}}=G u+C \frac{\partial u}{\partial t}
\end{gathered},
$$

gdzie $u(\dot{x}, t), i(\dot{x}, t)$ - przestrzenno-czasowe rozkłady napięcia i prądu wzdłuż linii. Dokonując modelowania cyfrowego z odstępem pobierania próbek czasowych $\theta$ otrzymuje się operatorowy układ równań różniczkowych:

$$
\begin{aligned}
& \frac{d u}{d \dot{x}}=\frac{L}{\theta}(a-z) i \\
& \frac{d i}{d \dot{x}}=\frac{C}{\theta}(b-z) u
\end{aligned},
$$

który po dalszych przekształceniach przyjmuje ostateczną postać:

$$
\begin{gathered}
\frac{d u}{d x}=\rho A i \\
\frac{d i}{d x}=\rho^{-1} B u
\end{gathered}
$$

gdzie:

$A(z)=a-z, \quad B(z)=b-z \quad-$ elementarne filtry cyfrowe nierekursywne rzędu 1-go;

$a=1+R / R_{L}, \quad b=1+G / G_{C} \quad$ - zera (rzeczywiste) filtrów elementarnych;

$\rho=\sqrt{R_{L} / G_{C}}$ - opór falowy linii;

$x=\sqrt{R_{L} G_{C}} \dot{X}-$ względna odległość mierzona od końca linii;

$R_{L}=L / \theta, \quad G_{C}=C / \theta \quad$ - rezystancja indukcyjna,

konduktancja pojemnościowa linii w $\Omega$ i $\Omega^{-1}$ na jednostkę długości.

W rozwiązaniu równań różniczkowych linii (11) biorą udział dwa operatory:

$$
\begin{aligned}
& \sqrt{A B}=(a-z)^{1 / 2}(b-z)^{1 / 2}, \\
& \rho \sqrt{\frac{A}{B}}=\rho(a-z)^{1 / 2}(b-z)^{-1 / 2} .
\end{aligned}
$$

Są one sekwencjami dwóch filtrów cyfrowych całkopochodnych rzędu $1 / 2$ i $\quad-1 / 2$ z zero-biegunami rzeczywistymi $a, b$ leżącymi poza domkniętym kołem jednostkowym. Pierwszy z nich określony wzorem (12) nazywa się filtrem propagacji, drugi (13) to filtr impedancji falowej. Ich współczynniki wagowe można wyznaczyć ze wzorów splotowych [2][3]:

$$
\begin{aligned}
& (\sqrt{A B})_{n}=\sqrt{a b} a^{-n} \alpha_{n}, \\
& \left(\sqrt{\frac{A}{B}}\right)_{n}=\sqrt{\frac{a}{b}} a^{-n} \beta_{n},
\end{aligned}
$$

gdzie:

$$
\alpha_{n}=\sum_{m=0}^{n}\left(\frac{a}{b}\right)^{m} D_{n-m} D_{m},
$$

$$
\beta_{n}=\sum_{m=0}^{n}\left(\frac{a}{b}\right)^{m} D_{n-m} I_{m} .
$$

Ciągi $\left\{D_{n}\right\}_{n=0}^{\infty},\left\{I_{n}\right\}_{n=0}^{\infty}$ są współczynnikami wagowymi filtrów:

- różniczkującego rzędu 1/2:

$$
D(z)=(1-z)^{1 / 2},
$$

- całkującego z rzędem $1 \frac{1}{2}$ :

$$
I(z)=(1-z)^{-1 / 2} .
$$

Wagi te określone są wzorem (8), który w tym przypadku przyjmuje postać:

$$
D_{n}=-\frac{1}{2} \frac{1}{4} \frac{3}{6} \frac{5}{8} \cdots \frac{2 n-3}{2 n}, \quad D_{0}=1,
$$

oraz:

$$
I_{n}=\frac{1}{2} \frac{3}{4} \frac{5}{6} \frac{7}{8} \cdots \frac{2 n-1}{2 n}, \quad I_{0}=1 .
$$

W rozwiązaniu równań operatorowych linii (11) występuje też operator funkcyjny złożony:

$$
e^{\sqrt{A B} x}
$$

tzw. operator - filtr transmisji falowej. Jego współczynniki wagowe można wyznaczać rekurencyjnie za pomocą wzoru (10):

$$
\begin{aligned}
& \left(e^{\sqrt{A B} x}\right)_{n}=x \sum_{m=1}^{n} \frac{m}{n}(\sqrt{A B})_{m}\left(e^{\sqrt{A B} x}\right)_{n-m} . \\
& \left(e^{\sqrt{A B} x}\right)_{0}=e^{a b x}
\end{aligned}
$$

\section{Periodyzacja stabilnych filtrów przyczynowych}

Każdy stabilny i przyczynowy filtr cyfrowy scharakteryzowany ciągiem wagowym $\left\{\gamma_{n}\right\}_{n=0}^{\infty}$ może być speriodyzowany, tzn. zamieniony w $N$-okresowy zgodnie z formułą [4]:

$$
\tilde{\gamma}_{n}=\gamma_{n}+\sum_{p=1}^{\infty} \gamma_{n+p N} \text { dla } n \in\{0,1, \ldots, N-1\} \text {. }
$$

Filtr periodyczny identyfikowany jest za pomocą ciągu $N$ okresowego $\left\{\tilde{\gamma}_{n}\right\}$ i działa na $N$-okresowy sygnał wejściowy $\left\{x_{n}\right\}$ formułą splotu cyklicznego:

$$
(\tilde{\gamma} x)_{n}=\sum_{m=0}^{N-1} \tilde{\gamma}_{n \ominus m} x_{m} \equiv\left\{\gamma_{n}\right\} \circledast\left\{x_{n}\right\},
$$

gdzie znak $\odot$ oznacza działanie odejmowania modulo $N$.

Otrzymane w poprzednim punkcie filtry $\sqrt{A B}$, $\sqrt{A / B}$ i $e^{\sqrt{A B}}$ są stabilne, bo ich ciągi wagowe należą do 
przestrzeni $\mathbf{L}^{1}$. Są również przyczynowe i dlatego mogą być speriodyzowane za pomocą formuły (19). Stabilność tych filtrów jest konsekwencją tego, że zera filtrów elementarnych $A, B$ leżą poza domkniętym kołem jednostkowym.

\section{Zniekształcenia modulacyjne filtrów cyfrowych}

Czasowo-dyskretny $\quad N$-periodyczny

zmodulowany opisany jest ciągiem:

$$
x_{n}(\tau): n \in\{0,1, \ldots, N-1\}, \tau \in \mathbf{R} .
$$

Ciąg ten jest okresowy podług czasowo-dyskretnego wskaźnika $n$, rzeczywisty parametr $\tau$ zwany czasem unoszenia powoduje powolną ewolucję sygnału modulację. W istocie sygnał analogowy zmodulowany scharakteryzowany jest funkcją czasową dwóch zmiennych $x(t, \tau)$ okresową podług $t$ o okresie $T$. Wprowadzony wcześniej ciąg $\left\{x_{n}(\tau)\right\}$ może powstawać poprzez próbkowanie sygnału analogowego podług $t \mathrm{z}$ odstępem pobierania próbek $\theta$

Można wykazać że modulacja powoduje zniekształcenie operatora przejścia układu $H(s), \quad s=d / d t$ według reguły [8]:

$$
H(s) \rightarrow H(s)\left(1+\frac{d \ln H}{d s} \frac{d}{d \tau}\right),
$$

gdzie $H(s)$ jest analogową transmitancją układu liniowego, czasowo-niezmienniczego, a więc działającego na sygnał wejściowy względem operacji splotu. Gdy sygnał ten jest okresowy podług zmiennej $t$ jest to splot cykliczny.

Jeżeli $H^{D}(z)$ jest modelem cyfrowym układu analogowego $H(s)$ otrzymywanym za pomocą funkcji digitalizującej $s=D(z)$, tzn. że:

$$
H^{D}(z)=H(D(z))
$$

wtedy formuła zniekształcenia modulacyjnego filtru cyfrowego przyjmie postać:

$$
H^{D}(z) \rightarrow H^{D}(z)\left(1+\left(\frac{d D}{d z}\right)^{-1} \frac{d \ln H^{D}}{d z} \frac{d}{d \tau}\right) .
$$

W szczególnym przypadku gdy funkcją digitalizującą jest $D(z)=\frac{1}{\theta}(1-z) \quad$ reguła (23) przyjmie następującą postać:

$$
\begin{aligned}
H^{D}(z) \rightarrow & H^{D}(z)\left(1-\theta \frac{d \ln H^{D}}{d z} \frac{d}{d \tau}\right)= \\
& =H^{D}\left(1+\Delta H \frac{d}{d \tau}\right)
\end{aligned},
$$

$$
\Delta H=-\theta \frac{d \ln H^{D}}{d z} .
$$

Operatory $H^{D}, \Delta H$ we wzorze (24) trzeba traktować jak speriodyzowane filtry cyfrowe, $z$ których ten pierwszy jest filtrem oryginalnym, drugi jako jego ujemna logarytmiczna pochodna jest deformacją modulacyjną. Filtr deformacji modulacyjnej zawiera też operator różniczkowania podług czasu unoszenia. Filtry $H^{D}$ i $\Delta H$ działają na sygnał wejściowy według prawa splotu cyklicznego wykonywanego po wskaźniku dyskretnym $n \in\{0,1, \ldots, N-1\}$. Wszystko to ilustruje schemat blokowy pokazany na rys. 1 .

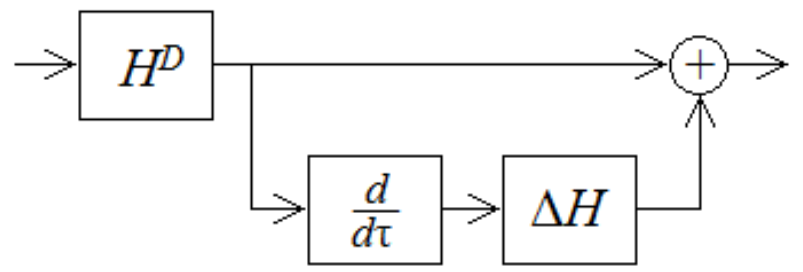

Rys. 1. Schemat blokowy filtru cyfrowego $z$ widocznym multiplikatywnym zniekształceniem modulacyjnym

Widoczny na rys. 1 jest kaskadowo dołączony filtr deformacji modulacyjnej w postaci logarytmicznopochodnego filtru $\Delta H$ i bloku różniczkowania podług czasu unoszenia.

\section{Zniekształcenia modulacyjne filtrów cyfrowych - modeli linii długiej}

W punkcie tym zostaną określone operatory cyfrowych logarytmiczno-pochodnych filtrów deformacyjnych dla filtru impedancji falowej $\rho \sqrt{A / B}$ oraz złożonego pierwiastkowo-wykładniczego filtru transmisji falowej $e^{\sqrt{A B} x}$.

Operator deformacyjny $\Delta H$ występujący we wzorze (24) i widoczny też w schemacie blokowym na rys. 1 dla operatora impedancji falowej przyjmuje postać:

$$
\begin{aligned}
& -\theta \frac{d \ln \rho \sqrt{\frac{A}{B}}}{d z}=-\frac{\theta}{2}\left(\frac{\frac{d A}{d z}}{A}-\frac{d B}{B z}\right)= \\
& =\frac{\theta}{2}\left(\frac{1}{a-z}-\frac{1}{b-z}\right)=\frac{\theta}{2} \frac{b-a}{(a-z)(b-z)}
\end{aligned}
$$

Jest on wymiernym rekursywnym filtrem cyfrowym rzędu 2-go z rzeczywistymi biegunami $a, b$ leżącymi poza domkniętym kołem jednostkowym co zapewnia jego stabilność.

Natomiast analogiczny deformacyjny operator dla filtru transmisji falowej określony jest wzorem:

$$
\begin{aligned}
& -\frac{d \ln e^{\sqrt{A B} x}}{d z}=-\theta x \frac{d \sqrt{A B}}{d z}= \\
& =-\theta x \frac{\frac{d A}{d z} B+A \frac{d B}{d z}}{2 \sqrt{A B}}=\frac{\theta x}{2}\left(\sqrt{\frac{A}{B}}+\sqrt{\frac{B}{A}}\right)
\end{aligned}
$$


Nie jest on już wymierny, a okazuje się sumą dwóch wzajemnie odwrotnych filtrów pierwiastkowych:

$$
\Delta H=\frac{\theta x}{2}\left[\begin{array}{c}
(a-z)^{1 / 2}(b-z)^{-1 / 2}+ \\
+(a-z)^{-1 / 2}(b-z)^{1 / 2}
\end{array}\right] .
$$

Jego współczynniki wagowe można wyznaczyć za pomoca formuł splotowych (15) i (17). Pierwiastkowy filtr $\sqrt{A / B}$ występujący w wyrażeniu (26) podobny jest do filtru cyfrowego impedancji falowej i wynosi dokładnie $Z_{f} / \rho$.

\section{Wnioski}

Linię długą charakteryzują dwa operatory: impedancji falowej $Z_{f}=\sqrt{Z / Y}$ i transmisji falowej $e^{x \sqrt{Z Y}}$. W sytuacji gdy przez linię przenoszone są sygnały zmodulowane ulegają one tzw. deformacji modulacyjnej. Oprócz filtru cyfrowego, który modeluje dany operator linii, pojawia się logarytmiczno-pochodny filtr deformacji modulacyjnej. Oryginalny filtr impedancji falowej jest opisany całkopochodnym operatorem rzędu $2 \times 1 / 2 \quad z$ zerobiegunem rzeczywistym, a odpowiadający mu deformacyjny filtr logarytmiczno-pochodny jest już zwykłym filtrem rekursywnym 2-go rzędu. Natomiast filtr transmisji falowej jest filtrem złożonym. Jest to filtr funkcyjny pierwiastkowo-wykładniczy i przez to jego filtr logarytmiczno-pochodny nie jest już opisany operatorem wymiernym ale złożony jest z pierwiastkowego operatora impedancji falowej i jego odwrotności.

Autorzy: dr inż. Zuzanna Siwczyńska, Politechnika Krakowska, Instytut Elektrotechniki i Informatyki, ul. Warszawska 24, 31-155 Kraków, E-mail: zsiw@pk.edu.pl.

\section{LITERATURA}

[1] Siwczyńska Z.: Cyfrowe filtry hiperboliczne i eliptyczne w zastosowaniach do układów o parametrach rozłożonych, Przegląd Elektrotechniczny, 92 (2016), nr 9, 238-242

[2] Siwczyńska Z.: Pierwiastkowe operatory immitancji realizacja za pomocą filtrów cyfrowych, Przegląd Elektrotechniczny, 91 (2015), nr 12, 265-266

[3] Siwczyńska Z.: Modele nieskończonych obwodów elektrycznych - operatory pierwiastkowe, Przegląd Elektrotechniczny, 91 (2015), nr 12, 262-264

[4] Siwczyńska Z.: Przyczynki do teorii mocy linii długiej w dziedzinie czasu dyskretnego, Przegląd Elektrotechniczny, 91 (2015), nr 3, 149-151

[5] Siwczyński M., Drwal A., Żaba S.: The digital function filters algorithms and applications, Bulletin of the Polish Academy of Sciences. Technical Science, 61 (2013), n. 2, 371-377

[6] Siwczyński M., Drwal A., Żaba S.: Zastosowanie cyfrowych filtrów hiperbolicznych rzędu ułamkowego do analizy procesów falowych, Przegląd Elektrotechniczny, 88 (2012), nr 5a, 218222

[7] Siwczyński M., Drwal A., Żaba S.: Zastosowanie cyfrowych filtrów rzędu ułamkowego typu wykładniczego do analizy układów o parametrach rozłożonych, Przegląd Elektrotechniczny, 88 (2012), nr 2, 184-190

[8] Siwczyński M., Hawron K.: Rozkłady G, B operatorów dwójników elektrycznych i ich zaburzenia modulacyjne, Przegląd Elektrotechniczny, 91 (2015), nr 10, 257-261

[9] Siwczyński M., Hawron K.: Rozkłady G, B operatorów zaburzonych modulacyjnie - realizacja za pomocą filtrów cyfrowych, Przegląd Elektrotechniczny, 92 (2016), nr 5, 212215

[10] Atici F. M., Eloe P. W.: A transform method in discrete fractional calculus, International Journal of Difference Equations (IJDE), 2 (2007), n. 2, 165-176

[11] Li Y., Sheng H., Chen Y. Q.: Analytical impulse response of a fractional second order filter and its impulse response invariant discretization, Signal Processing, 91 (2011), n. 3, 498-507

[12] Tseng C. C.: Design of FIR and IIR fractional order Simpson digital integrators, Signal Processing, 87 (2007), n. 5, 10451057

[13] Chen Y. Q., Vinagre B. M.: A new IIR-type digital fractional order differentiator, Signal Processing, 83 (2003), n. 11, 23592365

[14] Stakhiv P., Kozak Y., Hoholyuk O.: Discrete mathematical macromodel of electric transmission line, Przegląd Elektrotechniczny, 89 (2013), nr 4, 272-274 